OPEN ACCESS

Edited by:

Bronwen Cowie,

University of Waikato, New Zealand

Reviewed by:

Divya Varier,

George Mason University,

United States

Vanessa Scherman,

University of South Africa, South Africa

${ }^{*}$ Correspondence:

Kuen-Fung Sin

kfsin@eduhk.hk

Specialty section:

This article was submitted to

Assessment, Testing and Applied

Measurement,

a section of the journal

Frontiers in Education

Received: 02 March 2021 Accepted: 09 July 2021

Published: 27 July 2021

Citation:

Yan Z, Xiao $Y$, Sin $K-F$, Yang $L$ and

Guo $W$-Y (2021) Formative

Assessment Practices in Special School Classrooms With the Support

of E-Books: A Case Study.

Front. Educ. 6:674869.

doi: $10.3389 /$ feduc.2021.674869

\section{Formative Assessment Practices in Special School Classrooms With the Support of E-Books: A Case Study}

\author{
Zi Yan ${ }^{1}$, Yangyu Xiao ${ }^{2}$, Kuen-Fung $\mathrm{Sin}^{3 *}{ }^{*}{\text { Lan } \text { Yang }^{1} \text { and Wu-Yuan Guo }}^{1}$ \\ ${ }^{1}$ Department of Curriculum and Instruction, The Education University of Hong Kong, Hong Kong, China, ${ }^{2}$ School of Humanities \\ and Social Science, The Chinese University of Hong Kong, Shenzhen, China, ${ }^{3}$ Department of Special Education and Counselling, \\ The Education University of Hong Kong, Hong Kong, China
}

While formative assessment is recognised as a powerful strategy to improve student learning in mainstream education, less is known about its use in special schools. This study investigates how teachers' Personal Practice Assessment Theories (PPATs) affect their formative assessment practices in the special school context with the support of e-books. A case study was conducted with three Chinese teachers working with lower primary students who exhibit mild levels of intellectual disability. Data were collected through classroom observations and interviews. The findings reveal that the interaction between teachers' PPATs and the use of e-books affect teachers assessment goals, and the way they elicit, interpret and respond to assessment information. This study contributes to the understanding of how e-learning technology can be used to facilitate meaningful formative assessment in the special education context.

\footnotetext{
Keywords: formative assessment, special education, personal practice assessment theories, teaching practice, e-books
}

\section{INTRODUCTION}

Extensive research evidence has been collected on how formative assessment supports learning by identifying learning weaknesses and strengths, enhancing learning motivation and metacognition, supporting self-regulated learning, and providing informative feedback (Wiliam et al., 2004; Black and Wiliam, 2009; Yan et al., 2021). The design and implementation of formative assessment can be facilitated with an integration of e-learning tools, by creating assessment tasks to meet individual students needs, collecting students responses immediately, offering immediate feedback and promoting interaction among students (Pachler et al., 2010; Llamas-Nistal et al., 2013). However, formative assessment with the support of e-learning in the special school context, is still an under-explored topic. Another related issue in formative assessment is how teachers assessment belief may affect their assessment practices, as teachers are the key agents in implementing formative assessment in the classroom (Yan et al., 2021). Teachers bring a set of personal beliefs and perceptions into the classroom, which affects what and how they teach (Yan, 2014; Yan and Sin, 2014; Yan and Cheng, 2015). Thus, studies of formative assessment practices rely on a clear understanding of teachers beliefs about formative assessment. Recent research has used the concept of Personal Practice Assessment Theories (PPATs) (Box et al., 2015) as a means of interpreting teachers' practices. Hence, the current study aims to add to current knowledge by investigating how and in what way teachers' PPATs affect their assessment practices through a case study conducted in the primary sector of special education schools where e-learning tools were integrated with instructional practices. 


\section{Formative Assessment With E-Learning Tools in the Special Education Context}

The theoretical framework of this study amalgamates four themes: 1) formative assessment in special schools; 2) e-learning tools in special schools; 3) integrating formative assessment with e-learning tools; and 4) teachers' PPATs. Special schools in this study refer to schools that serve students with special educational needs.

\section{Formative Assessment in Special Education Schools}

Formative assessment is defined as a set of classroom procedures whereby evidence about student learning outcome is elicited, interpreted, and used by teachers, students, or their peers to make decisions about the next steps of learning and instruction that are likely to improve student learning (Black and Wiliam, 2009). Formative assessment can, thus, be regarded as a set of classroom practices, ranging from learner-centred activities to teacherdirected assessments (Carless, 2011; Guo and Yan, 2019). Hence, this study, in common with formative assessment studies in special education contexts, conceptualises formative assessment as an instructional strategy, embedded in daily classroom activities and conversations, which can identify the learning needs of special education students, so that modifications of instruction can be made and more support can be provided (Sanford et al., 2013).

Burns and Ysseldyke (2009) report that formative assessment is ranked as the fourth most frequently used practice by special school teachers and the second most frequently used practice by school psychologists in special schools. Teachers in special schools have been frequently observed employing a range of formative assessment activities such as informal discussion, the observation of level of participation, and practical problemsolving; these activities were considered to be an integral part of classroom teaching and help them understand pupils strengths and weakness (Martyn and Richard, 1998). Although there is little theoretical evidence to demonstrate that the use of formative assessment differs from regular schools to special schools, the fact is that, compared with formative assessment study in mainstream schools, the studies of formative assessment in special schools are still scarce (Hanafin et al., 2007).

\section{E-Learning Tools in Special Schools}

With the evolution of the Web, the definition of e-learning has evolved from read-only internet-based learning, to an era where machines and human beings can interact with each other (Choudhury and Pattnaik, 2020). Such changes have provided teachers with additional opportunities of offering students individualised support, so that students with special learning needs can learn in the way that works best for them (Cumming and Rodríguez, 2017). In a study of 39 students with special education needs from Spain, Fernández-López et al. (2013) identify that e-learning tools make it possible for teachers to customise and adapt applications to meet the needs of different users in special education contexts. For example, by adopting a mobile platform (based on iPad and iPod touch devices), teachers can tune the learning materials to meet different learning needs and the format can be made more easily accessible by modifying images, texts and sound, or requiring learners to interact with the content. These tailormade e-learning applications, thus, enable students with special education needs to maximise the value of different learning tasks. Fernández-López et al. (2013) reveal that the use of an e-learning platform provides positive learning outcomes in the development of students basic skills, including language, mathematics, environmental awareness, independence and social development.

With specific reference to the learning of reading, e-books have been found to be effective in reducing the burden of decoding during reading and, therefore, have a positive impact on students reading comprehension, in particular, for those students with special learning needs. Gonzalez (2014) reveals that e-books with text-to-speech narrations enhance the comprehension of students with reading disabilities measured by oral telling, probably because text-to-speech features in e-books scaffold readers and allow them to work effectively in their own zones of proximal development. E-books still have the features of traditional books, such as allowing readers to turn pages, adding a bookmark or taking notes (Labbo, 2000; Korat, 2010). Furthermore, e-books incorporate interactive elements such as pictures, music, sound effects, animations or specific activities considered supportive of learners reading (Shamir and Korat, 2006; Moody et al., 2010). Another benefit of e-learning is that students are able to receive instant feedback on their performance, which could assist their learning during and after their engagement with tasks (Keppell et al., 2006). Finally, when students are engaged in web-based assessment, they are found to repeatedly engage in the process of practicing, reflecting and revising as they can gain feedback immediately from the e-learning platform and revise their answers accordingly (Wang, 2010).

\section{Integrating E-Learning Tools with Formative Assessment}

The development of e-learning tools has assisted in the design and implementation of assessment procedures, through the creation of tests, the collection of student responses, automated scoring and reporting, and feedback giving and receiving (Llamas-Nistal et al., 2013). More importantly, formative assessment using e-learning tools has the potential to support productive teaching and learning due to the immediate interaction between teachers and learners (Pachler et al., 2010). Both teachers and learners have the chance to engage and communicate with evidence of learning and, therefore, an effective feedback loop is easier to establish. E-learning can also act as an effective avenue for peer assessment, as it allows students to assess their peers work and give feedback in an easily accessible and interactive manner (Chang and Chen, 2009). However, there are also setbacks in formative assessment in e-learning environments, such as a lack of specific standards for assessment, uncertainty of assessment accuracy, inconvenience in discussions, inattention to assessment results, and restrictions on uploading assignments (Abbasi Kasani et al., 2018; Abbasi Kasani et al., 2020). Furthermore, despite of the unique advantages of e-learning in individualised instruction and 
catering for special learning needs (Llamas-Nistal et al., 2013), studies about formative assessment in e-learning environments in the special education context are scarce. This is a clear research gap that the current study aims to address.

\section{Teachers' Personal Practice Assessment Theories}

There is a degree of consensus that teachers understanding, cooperation, and support for change is a necessity when initiating new practices (Hallinger, 2011; Yan, 2018; Yan and Brown, 2021). To build a framework which accounts for how teachers beliefs may affect their assessment practices, Box et al. (2015) propose a model of Personal Practice Assessment Theories (PPATs). PPATs refer to systematic theories or beliefs teachers have based on their experiences, which influence their decisionmaking processes and their assessment practices. More specifically, teachers' PPATs influence their purpose of assessment, which in turn affects how they plan, implement and reflect on the effectiveness of assessment activities, and decide whether modification is needed. Both PPATs and assessment practices are influenced by internally (such as teachers experiences) and externally (such as contextual factors) constructed contextual factors. However, formative assessment studies in the special education school context are still scarce, not to mention more focused studies with a clear guidance of PPATs as the framework. Hence, two research questions are put forward below:

1) What are the PPATs underline the three Chinese teachers formative assessment practices in classrooms supported by e-books?

2) How do teachers' PPATs influence their formative assessment practices in classrooms supported by e-books?

\section{METHODS}

\section{Setting}

The current study was conducted in three primary level special schools in Hong Kong where children experience mild levels of intellectual disability. E-books have been introduced in these schools as a teaching and learning tool with the purpose of enhancing the quality of learning and teaching. With funding support, hundreds of e-books have been developed across subjects, including Chinese Languages, Mathematics, Music, General Studies, Technology and Design and Science, at different levels. Teachers and students access all these e-books through the e-Learning platform. Learning in the built-up infrastructure was expected to be more interactive and interesting. However, in the initial stage of resource development, the practice of using e-books for teaching and assessment was not so popular among teachers. In regard to the school-based curriculum and conventional pedagogical practices, it took time for the teachers to gain skills and confidence in using the technology widely in the classroom teaching. Teachers of different subjects firstly started their planning and teaching in junior forms. In the years after, the use of e-books became regular in all subjects. Ethical approval was obtained from the university where the principal investigator of this project works. In Hong Kong, 41 out of the 61 special schools are schools for students with intellectual disabilities.

\section{Design of the Study}

Drawing on the literature above, we propose a revised PPAT framework by focusing mainly on the purposes and implementation of assessment, specifically, how teachers elicit, interpret and respond to assessment information (Black and Wiliam, 2009) in the special school context with the assistance of e-books (See Figure 1).

As indicated in Figure 1, teachers' PPATs are likely to influence teachers assessment purposes and, thereafter, influence their assessment practices, including how they elicit assessment information from students, how they interpret the information and how they respond, all of which are situated in the special school context where e-books are used as a tool for facilitating assessment practices.

Based on the preceding review and analysis of the literature, this study aims to fill the research gap by investigating the formative assessment practices of three Chinese teachers in three Hong Kong special schools with the support of e-books. A case study approach was adopted to explore teachers' PPATs and how such PPATs affect their assessment practices with the support of e-books, through multiple lenses and facets (Yin, 1994). More specifically, we included teachers from three different schools with diverse assessment practices, which allowed us to unpack the topic under investigation in diverse contexts. Data collected through both classroom observations and interviews allowed us to develop a thick description of teachers classroom practices and the influence of their personal beliefs on assessment and e-learning on their practices (Merriam, 2009).

\section{Participants}

This study applied a purposive sampling method for selecting participants (Patton, 2005) from whom, we could gain deep insights and understandings of formative assessment and e-learning in special schools. After initial classroom observations of nine teachers, we selected three from three different schools whom we had observed based on the following criteria: 1) willingness to participate in classroom observations and in-depth interviews; 2) showing observable diversity in adopting formative assessment practices and the use of e-books (i.e., frequency and mode of formative assessment using e-books); and 3) receiving different levels of training on using formative assessment in classrooms (as shown in Table 1). Including participants with different classroom practices enabled us to develop a wider understanding of the issues (Stake, 2006).

All three female teachers taught Chinese, and had some experience of using e-books in their own schools. They all worked with lower primary students who exhibit mild levels of intellectual disability (see Table $\mathbf{1}$ for a summary of participants profiles). All the teachers have been assigned pseudonyms starting with letter ' $\mathrm{T}$ '. 


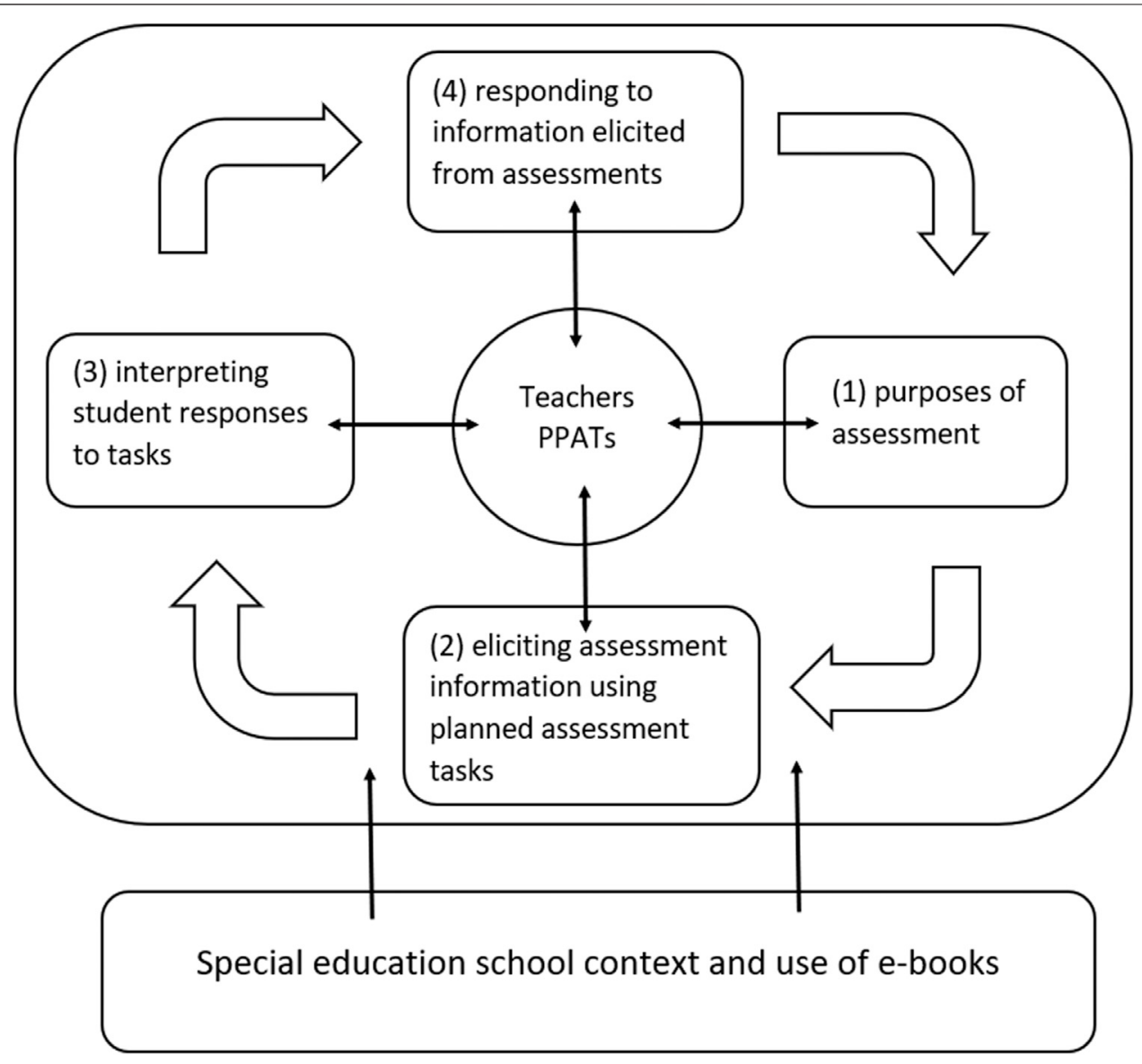

FIGURE 1 | Teachers PPATs framework in the special education context (modified from Box et al., 2015).

\section{Data Collection}

Two main means of data collection method, semi-structured interviews and classroom observations, were adopted to collect data regarding teachers formative assessment belief and practices. One $45 \mathrm{~min}$ lesson for each teacher was video-taped, at the same time as one researcher observed the lessons, and used to develop an understanding of teachers classroom practices. As teachers did not use e-books for each lesson, the observed lesson was selected when e-books were used. The research team members watched the $45 \mathrm{~min}$ lesson and drafted a summary of each participating teacher's PPATs before the interviews. The summary described how teachers elicited assessment information from students, how they used the information and how they responded to students, with the support of e-books. In addition, the research team transcribed and translated classroom episodes related to assessment practices, in the hope that these episodes would assist a better understanding of the relationships between teachers' PPATs and their actual assessment practices.

Semi-structured interviews were conducted two weeks after the classroom observations. Whereas the classroom observations offered a preliminary understanding of teachers assessment practices, semi-structured interviews allowed the research team

TABLE 1 | Profile of participating teachers.

\section{Participating teachers}

Types of learners

Experience of using e-books

Training received on using Regular in-service training

assessment

Training received on using

e-books
Tammy

Mild level of intellectual disability

One year

Training from service providers and the school

$\begin{array}{ll}\text { Teresa } & \text { Tracey } \\ \text { Mild level of intellectual disability } & \text { Mild level of intellectual disability } \\ \text { One year } & \text { Four months }\end{array}$

$2 \mathrm{~h}$ professional development training from the Education bureau plus ad-hoc in-service training Training from service providers and the school
A session on assessment from degree course completed; ad-hoc in-service training

Training from service providers and the school 
to explore teachers' beliefs and practices in-depth and, at the same time, kept the interviews among participants consistent (Newby, 2010). Each interview lasted for about 50-70 min. The interview questions were guided by our framework proposed in Figure 1, which include: 1) personal beliefs about learning in special schools; 2) personal beliefs about assessment in special schools; 3) personal beliefs about the role of e-books; 4) personal practices with assessment and using e-books in special schools; and 5) reflections on strategies in doing assessment and the use of e-books. The researcher summarised the PPAT of each participating teacher on site for the participating teacher to review and revise. To facilitate the discussion of classroom practices, the research team selected an episode of about $5 \mathrm{~min}$ from the classroom videos, which demonstrated the teacher's assessment practices, and played the videos to the respective teachers, for them to reflect on their practice. Using classroom observations data to guide interviews has been considered to be an effective way to elicit concrete responses from participants and understand their classroom practices (Carspecken, 1997).

Whereas we included only one classroom observation and one interview for each teacher, such a strategy could be acceptable for a small-scale exploratory study for two reasons: first, the three teachers were chosen based on our initial classroom observations of the nine teachers and demonstrated diverse features in their assessment practices. Second, as each interview lasted for about an hour, it provided rich and in-depth data.

\section{Data Analysis}

Both classroom observations and interviews data were analysed and coded within the same framework as shown in Figure 1. The data analysis was conducted in two steps. First, the video-taped classes were watched repeatedly to identify the participating teachers' PPATs, their assessment strategies, and the ways in which they used e-books. Next, the interview data were analysed to identify teachers' beliefs about assessment and using e-books, the rationale underlying their assessment practices and the interaction between teachers' PPATs, assessment practices, and the learning context with the support of e-books. We adopted inductive approach of coding, with the codes inductively generated from classroom observations and interviews (Merriam, 2009). Following the data analysis procedure suggested by Miles and Huberman (1994), the research team conducted a preliminary analysis of interviews and classroom observation videos; they first generated a list of codes, as emerging from the data. These codes were then merged and categorised into different key themes shaped by the PPATs framework. In other words, the framework shaped the foci of the analysis and the exact codes emerged from the data itself. Our major foci of the analysis include.

- identification of the participating teachers' PPATs, purposes of assessment, implementation of formative assessment (i.e., how the participating teachers elicited, interpreted and responded to the assessment information),

- their beliefs about the role of e-learning tools in formative assessment.
Regarding the detailed coding process, for example, eliciting answers from different students, offering immediate feedback, promoting interaction, identifying students' weaknesses were coded under the theme-teacher's belief about the role of e-books in formative assessment; peer assessment, questioning strategies, and providing immediate feedback were coded under the theme-teachers formative assessment strategies. All analyses were guided by the theoretical framework put forward in Figure 1.

\section{Trustworthiness}

The trustworthiness of this study was ensured in several ways. First, the research team worked collaboratively to examine the data and discussed the emerging key themes (Merriam, 2009). The second and the last author of the paper first analysed one interview transcript independently; after they reached an agreement on the initial set of codes, the codes were discussed and agreed by the rest of the team. Second, we attempted to triangulate and crosscheck data from the classroom observations and interviews (Lincoln and Guba, 1985; Merriam, 2009), so as to make sure all data sets included examples on teachers' PPATs and assessment purposes, beliefs about e-books, assessment strategies adopted, and how e-books were used to facilitate learning. Third, we conducted "member checking" or in other words "respondent validation", by showing the drafted PPATs to the respective teachers for their confirmation (Lincoln and Guba, 1985).

\section{Findings}

Although all three participating teachers believed in the central role of formative assessment in the special education context, they had distinct PPATs. We report the findings relevant to the three teachers one-by-one in the following sections. For each teacher, the findings are framed in a way to address the two research questions respectively. First, teachers' PPATs and their beliefs about e-books are reported. Then, how teachers' assessment practices were affected or guided by their PPATs, and roles of e-books are exemplified.

\section{Tammy's PPATs and Assessment Practices PPATs and Assessment Purposes}

Tammy's assessment decisions and practices have been guided by her PPATs from three aspects: 1) teachers should involve students actively in assessment, as active involvement would enhance their understanding of what they have learned; 2) classroom assessment with the assistance of e-books can offer instant feedback on students learning, so that teachers can adjust their instruction accordingly; and 3) asking questions can enhance student learning.

Tammy pointed out that assessment at special education schools should serve two main purposes: to identify students current level of learning and inform teachers instruction, and to group students into different teaching groups according to their ability levels. Summative marks did not play an important role in special schools. Tammy's responses demonstrate a clear formative orientation of assessment in special schools. 


\section{Belief about E-Books}

Tammy considered that e-books had a number of benefits including allowing students to share their answers easily, facilitating students to learn from peers answers or notice their weaknesses, and allowing teachers to grasp students understanding easily. Tammy also noted that teachers need to adapt the content of e-books to meet the needs of their students. However, Tammy also noted:

Considering the needs of our students, they need to have more communication with people (rather than a device) when they worked on iPads, they would not pay full attention to you. (Tammy_LL198-200)

Tammy's responses show that whereas e-books can cater for individual students needs, they may also distract students; thus, teachers need to consider characteristics of the respective students when they integrate e-books in formative assessment.

\section{Tammy's Assessment Strategies}

Tammy was observed to use two assessment strategies frequently in class: questioning and peer assessment. She asked questions frequently to elicit information about students' understanding. Examples of questions are:

This boy is high. Look at this girl, she is...? How is she? (Tammy_video 1_08:24-08: 30)

What is this word and what is its antonym? (Tammy_video 2_07:23-07:26)

Asking questions can refine students understanding. In the example below, Tammy noticed that a student (referred as S1 here) had difficulties in figuring out the position of the aeroplane. She then responded to this student with further questions:

Tammy: S1. Is the aeroplane above the bird, or below the bird?

S1 used his gesture to indicate that the aeroplane is below the bird. Tammy bought the e-book to S1.

Tammy: S1, point it to me. Where is the aeroplane?

S1: The aeroplane is below.

Tammy: Point to the aeroplane on the e-book. Which one is the aeroplane?

S1 pointed to the aeroplane.

Tammy: Good job! Is aeroplane above or below the bird?

Students and S1: Above. (Tammy_video 1_11: $53-12: 38)$

The episode above exemplifies how Tammy used questions to elicit information about S1's understanding and helped S1 get the correct responses. An e-book was used as a facilitating tool. When S1 interacted with Tammy, all the students observed S1's response from the screen. Tammy responded with her rationale of asking questions:
I asked questions to check if they can answer the questions correctly. If they cannot get it right, I would try to figure out why - did they know the answers or not? (Tammy_LL 368-371)

Tammy's response shows that she used questioning as a strategy to understand student learning. It also implied that with the assistance of e-books, Tammy could easily ask students to re-work the exercise to refine their understanding. Thus, e-books worked as a facilitative tool for the teacher to elicit information about student learning.

When Tammy responded to S1's answer, she managed to ask further questions to elicit the correct answer gradually instead of telling the correct answer directly. Tammy's questioning strategy appeared to be guided by her first and third PPATs that teachers need to engage students actively in assessment and questioning which can enhance student learning. Questioning has been considered to be a powerful formative assessment strategy as it can help with eliciting, interpreting and using evidence to move learning forward (Black and Wiliam, 2009; Jiang, 2014).

Another assessment strategy Tammy frequently used was peer assessment. After collecting student responses through e-books, she invited students to review and comment on peers' answers. Tammy responded in the interviews that using e-books facilitates the process of peer assessment:

Once I pressed the button, I could see all the answers who got it right, who got it wrong, or who were on half way. Then, all students can see whether their peers know how to make up a sentence using certain words or not. (Tammy_LL 87-91)

The above response shows that e-books were considered as an effective tool in eliciting students responses, allowing the teacher to collect responses from different students, which was influenced by Tammy's first PPAT that students should be involved actively in the classroom.

\section{Role of E-Books in Formative Assessment}

In Tammy's class, e-books appeared to support formative assessment in two ways: eliciting answers from different students and offering immediate feedback. To elicit answers from different students, we observed that she walked around and asked them to use the "arrow" on the screen to identify and read out two words that were antonyms, for example, "high" and "low". The students choices could be easily displayed on the screen so that the whole class were able to observe their peers performance. After students completed their exercises, Tammy displayed answers from different students on the screen. Tammy noted:

When I asked students to put up their hands to answer the questions, some students were shy and they did not put up their hands. With e-books, every student can submit their answers. It's easy for teachers to collect answers from all students. (Tammy_LL 318-320) 
Such a strategy shows that Tammy tried to involve as many students as possible to check their understanding, which was guided by her first PPAT that students need to participate actively in assessment. E-books facilitated this process by allowing multiple submissions so that all students could work on the same task at the same time.

E-books also made it possible for Tammy to respond to the students' answers with instant feedback. In the example below, she noticed that students had difficulties in distinguishing two antonyms - "near" and "far" immediately after they had submitted their answers through e-books. Tammy worked with whole class and asked them to compare the distance of the two people away from them, thus, eliciting the right answer:

Tammy: This answer is not correct. But don't worry. Let's work on it together. (Tammy pointed to the word "far".) How to pronounce this word?

(Students did not give any responses, so Tammy played the audio on the iPad. The speaker said - "jyun5" [far]).

Tammy: Can you all repeat? One, two, three

Students: jyun5 (far)

Tammy: What does "far" (jyun5) indicate? Is the distance long, or short? (Tammy tried to demonstrate the long distance and short distance using her arm.)

Students: Long.

Tammy: Yes. When the distance is long, we use the word "far" (jyun5). Let's now look at the screen. Let me make the picture bigger (so that students can see clearly). Where is Siu Ming? Siu Ming is here, and $\mathrm{Siu} \mathrm{Zi}$ is here. Is the distance that Siu Ming is away from us long or short?

Students: Long and far.

Tammy: Yes. The distance is long. So, the answer is (Tammy waited for $3 \mathrm{~s}$ ) Shall we use "near" (gan6) or "far" (jyun5)?

Students: jyun5 (far) (Tammy_video 2_00:05-01:15)

The scenario above demonstrated how Tammy responded to the students' deficiency in understanding after she noticed that they could not articulate clearly the two concepts - "near" (gan6) and "far" (jyun5) by using the concepts they already know - "long" and "short". In this example, e-books helped Tammy identify the students difficulty immediately so as to provide instant feedback. Furthermore, e-books facilitated the learning process by offering the sound effect (e.g., pronouncing words) and altering the size of the picture so that all the students could view it clearly. Tammy's assessment practice in this example seemed to be guided by her second PPAT that e-books offer the chance for instant feedback so that teachers can adjust their instruction accordingly.

\section{Teresa's PPATs and Assessment Practice PPATs and Assessment Purposes}

Teresa's PPATs include three aspects: 1) classroom assessment is used to check if students follow the pace of instruction; 2) peer assessment should be encouraged as it enhances students understanding of the subject matter; and 3) teachers can understand students learning progress by assessing how students memorised and used what have been learned.

As Teresa noted, unlike mainstream schools which pay more attention to students learning outcomes for a summative purpose, assessments at special schools mainly serve a formative purpose. Assessments are mainly used to collect information on students learning progress so that teachers can make follow-up instruction(s) accordingly.

\section{Belief About E-Books}

Teresa considered that with the assistance of e-books, students were more motivated to learn, and more able to concentrate on doing their tasks, as videos and audios in e-books can arouse their interest (Teresa_LL 229-230). In addition, with the assistance of e-books, teachers can retrieve information regarding student learning quickly after assessment, as shown below:

Immediately (after they submitted their answers), I can get their performance - who got it right and who got it wrong. (Teresa_LL 287-289)

However, Teresa noted that as students can simply drag answers or words to different boxes, she was uncertain whether they had really understood the questions. She exemplified with an example of assessing students understanding of "interrogative sentence" using e-books:

I asked students to work on "interrogatives", "modal particles" and "punctuations". They simply dragged three words to three boxes. I was worried whether they really thought about the questions carefully. Without e-books, I can ask them more questions and give them more choices using word cards. The whole process will become more thought-provoking. (Teresa_LL 187-196)

Teresa's response shows the concerns teachers may have in using e-books, implying that more training can be provided, or more thought-provoking tasks that meet teachers needs can be developed.

\section{Teresa's Assessment Strategies}

In the class we observed, Teresa focused on the use of classifiers in Chinese. Classifiers, such as-a bottle of (water) and a piece of (bread), were important words frequently used in Chinese. The examples of classifiers Teresa used are presented in Appendix Table A1. Teresa was observed to use questioning strategy and peer assessment frequently. At the beginning of the lesson, Teresa drew students attention to examples of missing classifiers (for example, when saying one cat, “jat1 siu2 maau1” (一小貓) (incorrect response) instead of “jat1 zi2 siu2 maau1” (一隻小 貓) (correct response) is used by asking questions: 
I noticed some mistakes in this sentence. Have any students found that too? (Teresa_video 1_01:57-02:02)

What is missing in this sentence? (Teresa_video1_02: 17-02:22)

These questions appeared to serve the purpose of eliciting students understanding on the use of classifiers. The classroom observation demonstrates that Teresa's questions drew students attention to the missing classifiers and they were engaged by responding with how they would say the sentence with classifiers.

At the end of the lesson, Teresa asked questions to check whether students were able to recall what they had learned in the lesson. For example,

What are the four classifiers we learned today? (Teresa_video 1_45:50-46: 00)

Do you still remember? When will we use隻 [zi2]?

(Teresa_video 2_00:12-00:14)

Teresa acknowledged the importance of eliciting students' responses in class. Students' responses to teachers' questions or their reactions can help with generating feedback information, such as whether they understand what has been taught in class, or whether they have followed the pace of teaching (Teresa_LL 148-150; 159-163).

Teresa's questioning strategies seemed to be guided by her first and third PPATs that classroom assessment is used to check if students follow the pace of instruction, and to understand how they memorised and used what they had learned in class. Examples of peer assessment were also observed in Teresa's class. In the episode below, after submitting their answers, students noticed immediately on the screen that two of them did not get their answers correct.

SS: Someone got it wrong.

Teresa: Right. Let's look at their answers first.

Teresa picked out one student's responses with incorrect answers.

Teresa: Which question was answered incorrectly?

Students answered in chaos.

Teresa: Put up your hands, please. Alright, S5.

S5: "jat1 go3 sail gwaal" (the incorrect answer on the screen is "jat1 jek3 sail gwaal") (one watermelon)

Teresa: Is “jat1 jek3” correct?

S5: No.

Teresa: When do we use "jek3"?

S5: Before the animals.

Teresa: Right, “jek3” should be used before the animal.

(Teresa_video 1_25:45-32:07)

The above episode exemplified how e-books supported peer assessment by inviting students to evaluate and comment on peers' answers. Teresa explained her rationales for such a practice:

Every student could see how peers answered the questions. If peers answer the questions incorrectly, he (she) can comment on the answers and the classroom learning becomes more interactive. $\mathrm{He}$ (she) can also compare his (her) answers with peers and check if he (she) got answers correctly. (Teresa_LL 435-438)

Peer assessment was a prominent feature in Teresa's class, with or without the assistance of e-books. Her practices on peer assessment were apparently guided by her second PPATs, i.e., peer assessment should be encouraged, as peer assessment enhances students understanding of the subject matter.

\section{Role of E-Books in Formative Assessment}

Teresa believed that e-books allowed teachers to provide instant feedback on students performance and promoted interaction in assessment. In the example below, Teresa tried to elicit answers from different students:

Teresa: Now, I would invite one student to tell us where to put the classifier? (Several students put up their hands). S1, can you come out and answer the question?

Teresa: Shall we put the classifier at the beginning, middle or the end of a phrase?

S1 used the arrow on the screen to indicate that the classifier should be put at the beginning.

Teresa: S1 said classifier should be put at the beginning. Is that right?

Students: Not right.

Teresa: Anyone has a different answer?

Some students put up their hands.

Teresa: Okay, S2, come out and tell us.

S2 used the arrow to indicate that the classifier should be put at the end of the sentence.

Teresa: Emm. . S2 said the classifier should be put at the end of a sentence. Is that correct?

Some students responded, "Yes" and others responded "No".

Teresa: S3, you come and have a try.

S3 indicated that the classifier should be put in the middle, between 'jat1' (一) and “siul fong4 jyun4” (消 防員).

Teresa: Which classifier should be put here? Do you have any idea?

S3: go3 (個). “jat1 go3 siul fong4 jyun4” (一個消防員). (One firefighter)

Teresa: Alright. Let's look at the answer together.

Teresa clicked the answer-it turns out to be - "jat1 wai2 siu1 fong4 jyun4" (一位消防員). 
(Teresa_video 2_04:01-06:15)

In the example above, Teresa attempted to elicit answers from different students, in particular, when the first two students did not respond correctly. By displaying their answers on the screen for discussion, E-books helped Teresa to grasp the understanding of the classifier from different students, and offer immediate feedback.

\section{Tracey's PPATs and Assessment Purposes PPATs and Assessment Purposes}

Tracey's PPATs include three aspects: 1) classroom assessment is mainly used to check if students follow the pace of teaching towards completing the learning tasks; 2) when doing assessment, teachers need to check if students can recall and use what have been taught; and 3) teachers should keep to the lesson plan with less need to adjust instruction. Tracey considered the main purpose of assessments was to promote teaching and learning and summative tests did not play an important role. More specifically, assessments elicited information on student learning and informed teachers what students have learned and what they have not.

\section{Belief about E-Books}

Tracey noted that a major benefit of assessing through e-books was that e-books made teaching interesting; and students were more interested in responding to her questions. She also noticed that e-books helped her to collect evidence of students learning instantly. As Tracey noted:

When conducting assessment in the traditional way, I need to walk around to check if they got answers correct. Now I can see instantly who completed the exercises fast and who did the best job. (Tracey_ LL 177-179)

Whereas Tracey was aware of the role of e-books in assessment, she regarded e-books as an added-on material. In addition to the use of e-books, she would still use a wide range of assessment methods, such as dictation, tests, and observations. E-books were only used as an assistance to help her collect information about student learning (Tracey_LL203-205). The lack of integration of e-books into daily teaching was probably because Tracey only had two-month experience of using e-books. She had only attended several workshops on using e-books and was still learning by doing (Tracey_LL 29-38). She admitted that she used e-books mainly for teaching and had not got chance to study the functions related to assessment in detail (Tracey_LL 216-215). Such response indicated that the lack of training may affect the effective use of e-books.

\section{Tracey's Assessment Strategies}

The major assessment strategy observed in Tracey's class was questioning. She also asked a number of questions, for example:

Any students have difficult in understanding any words? (Tracey_video_05:40-05:43)
Is this (picture) a kitchen? Is this one "watering"? How about this one? Does the student get the answer correct? (Tracey_video_11:06-11:16)

What is the first picture about? How about the second picture? How about the third one? (Tracey_video_19: 28-19:49)

The above examples show that Tracey's questions were mainly used to check students understanding. In the first example above, after asking questions, Tracey went through all the keywords that students were going to practice, to make sure they had understood these words, which included: "market", "park", "kitchen", "digging" and "doll”. Her questions were mainly related to recalling vocabulary, which was guided by her second PPATs that when doing assessment, teachers need to check if students can recall and use what have been taught.

Tracey was aware of the role of questioning in assessing students understanding. She noted that questions helped with documenting information about students learning, although students may not necessarily notice that they have been assessed (Tracey_ LL 88-96). Peer assessment was not observed in Tracey's class. This was probably related to her assessment belief that assessment should mainly be implemented by teachers through observations, classroom tasks and homework. Whereas Tracey believed that the purpose of assessment was to promote learning, it seems that her assessment practices still focused on identifying weaknesses instead of enhancing learning, which can only be regarded as formative assessment practices in a restricted way.

\section{Role of E-Books in Formative Assessment}

In Tracey's lesson, e-books were used to do exercises. We observed that one strategy she used was to respond to students' answers and announce the first three students who completed the exercises. Then, she asked the whole class to read out these answers. In one instance, Tracey noticed that S4 got the answer incorrect. She picked the answer out for the whole class to comment:

Tracey: Let's look at S4's answer. What is the picture in the middle? Is this digging?

Students: No.

Tracey: How about this one? Is this one a "market"?

Students: No.

Tracey: Does it matter if someone got the answer wrong?

Students: Does not matter.

Tracey walked to the students who got the answers wrong.

Tracey: Click the reset. You can do it again. If you do not know how to answer, you can click the button next to each picture-it will pronounce the word to you.

Tracey then helped the students with clicking different buttons until S4 got all the answers correct.

(Tracey_video 1_21:13-22:46) 
In the above episode, the e-books acted as a tool for identifying S4's weakness and Tracey responded to the incorrect answers immediately. However, it seemed that she did not elicit correct answers from S4 and, thus, did not turn the assessment into an effective chance for learning. In the interview, Tracey noted that e-books provide chances for students to review each other's answers, which would not be possible when they worked on their own worksheets in written forms and she believed that e-books enhanced the chances for interaction (Tracey_LL 359-364). Tracey elaborated that she would demonstrate both correct and incorrect answers to students, as they can learn from incorrect responses of other students as well (Tracey_LL 370-373).

Whereas Tracey was fully aware of the role of e-books in eliciting information on student learning and supporting peer assessment, the way she responded to incorrect answers seemed to be largely teacher-dominated and peers only interacted at a surface level by pointing out the correctness of peers' answers. In other words, there was little evidence that correct responses were elicited from students step-by-step nor further discussion on the incorrect answers. The way Tracey responded to incorrect answers seemed to be guided by her first and third PPATs. She was aware that the classroom assessment was used to check if students were following the pace of teaching; but as she considered that following the lesson plan to be important, she spent little time in eliciting students correct responses step-bystep. Instead, Tracey asked S4 to press the button which pronounced the picture for him. To what extent such practice can contribute to the real understanding of the word remains unknown.

\section{DISCUSSION}

The current study reveals that the three special school teachers had distinct Personal Practice Assessment Theories (PPATs). The current study contributes to the understanding of how PPATs may affect teachers assessment practices with the support of e-books in the special education context. In general, all three believe that formative (rather than summative) assessment should play a central role in the special education context, confirming that formative assessment is a commonly used strategy in the special education context (Martyn and Richard, 1998). The three teachers did, however, have diverse views regarding how such a conception of formative assessment can be put into their daily classroom practices. Tammy's PPATs emphasised the active role of students in assessment and using a variety of assessment strategies (including peer assessment, questioning and adjusting instruction) to enhance understanding. Tracey's PPATs were the least student-centred, in that she viewed the main role of assessment was to check if students follow the pace of teaching. She did not think it necessary to adjust her pace of instruction. Teresa's PPATs were a mixture. While she emphasised the role of assessment in checking students' learning progress and whether they followed the teachers' instruction, she values students engagement through peer assessment.
The current study supports the contention that teachers' PPATs affect their assessment practices (Box et al., 2015) and teachers' assessment practices can be explained to a large extent by their PPATs. More specifically, in the current study, we found that teachers' PPATs affected their assessment goals, and the strategies they used to elicit, interpret, and respond to the assessment information, which are the three key stages in the cyclical process of formative assessment. All three stages are informed by the teachers' perceived assessment purposes and guided by their own PPATs.

The findings visualise the PPATs framework we put forward in Figure 1. PPATs were central to the four aspects of formative assessment practice: 1) purposes of assessment; 2) eliciting assessment information using planned assessment tasks; 3) interpreting student responses to tasks; and 4) responding to information elicited from assessments, which were influenced by contextual factors and the use of e-books. In the cases where similar assessment strategies were used, the purposes of the related strategies and how teachers responded to information elicited from the assessments varied and were affected by their respective PPATs. For example, although all teachers used questioning strategies, Tammy's questions focused more on checking students understanding and identifying any misunderstanding while Tracey's questions focused on if students were able to recall fact knowledge that they had learned. Another example is related to how teachers elicited answers from different students and responding to that information. Tracey mainly elicited simple answers and did not have too much follow-up interaction with students on the content. Tammy and Teresa, however, had more follow-up interaction with students to make sure they understood what they have discussed. Thus, it is evident that teachers' assessment practices were influenced by their PPATs. In view of the crucial status of teachers' PPATs in affecting teachers' assessment practices as identified in the current study, future studies in this area can focus on decision-making, as teachers are more likely to use assessment to facilitate student learning when they believe in the value of certain practices. The diverse practices also indicate discrepancies between the three teachers' understanding of formative assessment and the state-of-the-art principles of formative assessment. Whereas all three teachers believed that formative assessment should play an important role in the special education context, Tracey's actual assessment practices were less formative, as her assessment practices focused mainly on checking the understanding and the correctness of the answers (for example, if S4 selected right vocabulary for the respective pictures). This indicates that further teacher professional development on formative assessment is still needed in the special education school context.

In addition to contributing to the growing body of knowledge about how teachers' PPATs affect teachers' assessment practices, the current study also contributes to the evidence how e-learning technology, i.e., e-books, can be used to support assessments in the special education context. The current study demonstrates the usefulness of e-books in facilitating formative assessment (Llamas-Nistal et al., 2013) and highlights the importance of supporting measures for teachers' implementation of formative 
assessment (Yan, 2021). The findings support that e-books can facilitate the process of formative assessment and support the needs of students at special schools through eliciting responses from various students, providing immediate feedback to students, facilitate classroom interaction, offer chance(s) for peer assessment, and allow teachers to reward positive behaviours of students with special education needs (Pachler et al., 2010; Llamas-Nistal et al., 2013). In considering the needs of students at special schools in the current study, e-books appeared to facilitate the learning process by providing learning materials appropriate at their own levels, and supporting the assessment procedures with audio and video aids. Such support is likely to help students with special education needs to succeed in completing tasks and decrease the achievement gap that exists between those without disabilities (Hall, Hughes, and Filbert 2000). The study also suggests that teachers were more likely to use technology in a more competent manner when they were more familiar with it and when they have received more training (Chiang and Jacobs, 2010). Whereas teachers in the special education context supported the use of e-books in general, they were also aware that e-books should supplement traditional books rather than fully substituting them, considering the characteristics of students in the special education school context and the nature of Chinese language learning.

\section{CONCLUSION}

The current study is among the first few exploratory studies investigating how teachers' PPATs affect their assessment practices with the assistance of e-books in the special schools context. Whereas all teachers believed formative assessment should be adopted in the special education school context, their PPATs influenced how they elicited, interpreted and responded to assessment information. E-books appeared to facilitate teachers' assessment practices in the special school context by supporting the interaction and special learning needs through facilitating peer assessment, providing immediate feedback, and offering learning materials with audio and visual aids. The current study contributes to the knowledge base of the impact of teachers' PPATs by taking

\section{REFERENCES}

Abbasi Kasani, H., Haji Zeynalgabedini, M., and Raisi, A. (2018). Pathology of University of Medical Sciences E-Learning System Based on Khan Model. J. Med. Educaion Develop. 12, 227-238.

Abbasi Kasani., H., Shams Mourkani, G., Seraji, F., and Abedi, H. (2020). Identifying the Weaknesses of Formative Assessment in the E-Learning Management System. J. Med. Edu 19, e108533. doi:10.5812/jme.108533

Black, P., and Wiliam, D. (2009). Developing the Theory of Formative Assessment. Educ. Asse Eval. Acc. 21, 5-31. doi:10.1007/s11092-008-9068-5

Box, C., Skoog, G., and Dabbs, J. M. (2015). A Case Study of Teacher Personal Practice Assessment Theories and Complexities of Implementing Formative Assessment. Am. Educ. Res. J. 52, 956-983. doi:10.3102/0002831215587754

Burns, M. K., and Ysseldyke, J. E. (2009). Reported Prevalence of Evidence-Based Instructional Practices in Special Education. J. Spec. Educ. 43, 3-11. doi:10.1177/0022466908315563 into consideration e-learning tools within the special school context. It is evident that e-learning tools were beneficial to learning and teaching in special schools. The findings shed lights to enhance quality learning and teaching in special schools for students with different categories of disabilities. Given that the current study only focused on teachers' formative assessment practices at a specific point of time, further studies may investigate the changes in teachers formative assessment practices over a prolonged period of time.

\section{DATA AVAILABILITY STATEMENT}

The raw data supporting the conclusions of this article will be made available by the authors upon reasonable request.

\section{ETHICS STATEMENT}

The studies involving human participants were reviewed and approved by The Education University of Hong Kong. The patients/participants provided their written informed consent to participate in this study.

\section{AUTHOR CONTRIBUTIONS}

ZY conceived of the presented idea and developed the theoretical framework. ZY, and YX prepared the first draft of the manuscript. KS supervised the project that generated data for this manuscript. All authors discussed the results and contributed to the final manuscript.

\section{ACKNOWLEDGMENTS}

The authors make thanks and acknowledgement to the "Project of Special schools school-based learning materials digitization scheme", funded by the HSBC 150th Anniversary Charity Program.

Carless, D. (2011). From Testing to Productive Student Learning: Implementing Formative Assessment in Confucian-Heritage Settings. New York, NY: Routledge.

Carspecken, P. F. (1997). Critical Ethnography in Educational Research: A Theoretical and Practical Guide. New York, NY: Routledge.

Chang, T.-Y., and Chen, Y.-T. (2009). Cooperative Learning in E-Learning: A Peer Assessment of Student-Centered Using Consistent Fuzzy Preference. Expert Syst. Appl. 36, 8342-8349. doi:10.1016/j.eswa.2008.10.050

Chiang, H.-Y., and Jacobs, K. (2010). Perceptions of a Computer-Based Instruction System in Special Education: High School Teachers and Students Views. Work 37, 349-359. doi:10.3233/wor-2010-1089

Choudhury, S., and Pattnaik, S. (2020). Emerging Themes in E-Learning: A Review from the Stakeholders' Perspective. Comput. Educ. 144, 103657. doi:10.1016/ j.compedu.2019.103657

Cumming, T. M., and Draper Rodríguez, C. (2017). A Meta-Analysis of Mobile Technology Supporting Individuals With Disabilities. J. Spec. Educ. 51, 164-176. doi:10.1177/0022466917713983 
Fernández-López, Á., Rodríguez-Fórtiz, M. J., Rodríguez-Almendros, M. L., and Martínez-Segura, M. J. (2013). Mobile Learning Technology Based on iOS Devices to Support Students With Special Education Needs. Comput. Educ. 61, 77-90. doi:10.1016/j.compedu.2012.09.014

Gonzalez, M. (2014). The Effect of Embedded Text-To-Speech and Vocabulary Ebook Scaffolds on the Comprehension of Students with Reading Disabilities. Int. J. Spec. Educ. 29, 111-125.

Guo, W. Y., and Yan, Z. (2019). Formative and Summative Assessment in Hong Kong Primary Schools: Students' Attitudes Matter. Assess. Educ. Princ. Pol. Pract. 26, 675-699. doi:10.1080/0969594X.2019.1571993

Hall, T. E., Hughes, C. A., and Filbert, M. (2000). Computer Assisted Instruction in Reading for Students with Learning Disabilities: A Research Synthesis. Educ. Treat. Child. 23, 173-193.

Hallinger, P. (2011). Leadership for Learning: Lessons From 40 Years of Empirical Research. J. Educ. Admin 49, 125-142. doi:10.1108/09578231111116699

Hanafin, J., Shevlin, M., Kenny, M., and Neela, E. M. (2007). Including Young People with Disabilities: Assessment Challenges in Higher Education. High Educ. 54, 435-448. doi:10.1007/s10734-006-9005-9

Jiang, Y. (2014). Exploring Teacher Questioning as a Formative Assessment Strategy. RELC J. 45, 287-304. doi:10.1177/0033688214546962

Keppell, M., Au, E., Ma, A., and Chan, C. (2006). Peer Learning and Learningoriented Assessment in Technology-Enhanced Environments. Assess. Eval. Higher Educ. 31, 453-464. doi:10.1080/02602930600679159

Korat, O. (2010). Reading Electronic Books as a Support for Vocabulary, Story Comprehension and Word Reading in Kindergarten and First Grade. Comput. Educ. 55, 24-31. doi:10.1016/j.compedu.2009.11.014

Labbo, L. D. (2000). 12 Things Young Children Can Do with a Talking Book in a Classroom Computer Center. Reading Teach. 53, 542-546.

Lincoln, Y. S., and Guba, E. G. (1985). Naturalistic Inquiry. Newbury Park, CA: Sage.

Llamas-Nistal, M., Fernández-Iglesias, M. J., González-Tato, J., and Mikic-Fonte, F. A. (2013). Blended E-Assessment: Migrating Classical Exams to the Digital World. Comput. Educ. 62, 72-87. doi:10.1016/j.compedu.2012.10.021

Martyn, R., and Richard, A. (1998). Assessment and Special Educational Needs: Teachers' Dilemmas. Br. J. Spec. Educ. 25, 81-87.

Merriam, S. B. (2009). Qualitative Research: A Guide to Design and Implementation. San Francisco, CA: John Wiley \& Sons.

Miles, M. B., and Huberman, A. M. (1994). An Expanded Sourcebook: Qualitative Data Analysis. 2nd Edn. Thousand Oaks: SAGE Publication.

Moody, A. K., Justice, L. M., and Cabell, S. Q. (2010). Electronic versus Traditional Storybooks: Relative Influence on Preschool Children's Engagement and Communication. J. Early Child. Literacy 10, 294-313. doi:10.1177/ 1468798410372162

Newby, P. (2010). Research Methods for Education. Harlow, UK: Person.

Pachler, N., Daly, C., Mor, Y., and Mellar, H. (2010). Formative E-Assessment: Practitioner Cases. Comput. Educ. 54, 715-721. doi:10.1016/ j.compedu.2009.09.032

Patton, M. Z. (2005). "Qualitative Research," in Encyclopedia of Statistics in Behavioral Science. Editors B. S. Everitt and D. C. Howell (Chichester: John Wiley \& Sons), 341-346.

Sanford, A. K., Park, Y., and Baker, S. K. (2013). Reading Growth of Students with Disabilities in the Context of a Large-Scale Statewide Reading Reform Effort. J. Spec. Educ. 47, 83-95. doi:10.1177/0022466911430350
Shamir, A., and Korat, O. (2006). How to Select CD-ROM Storybooks for Young Children: The Teacher's Role. Reading Teach. 59, 532-543. doi:10.1598/ rt.59.6.3

Stake, R. E. (2006). Multiple Case Study Analysis. London: The Guildford Press.

Wang, T.-H. (2010). Web-based Dynamic Assessment: Taking Assessment as Teaching and Learning Strategy for Improving Students' E-Learning Effectiveness. Comput. Educ. 54, 1157-1166. doi:10.1016/ j.compedu.2009.11.001

Wiliam, D., Lee, C., Harrison, C., and Black, P. (2004). Teachers Developing Assessment for Learning: Impact on Student Achievement. Assess. Educ. Principles, Pol. Pract. 11, 49-65. doi:10.1080/0969594042000208994

Yan, Z. (2021). Assessment-as-learning in Classrooms: The Challenges and Professional Development. J. Educ. Teach. 47, 293-295. doi:10.1080/ 02607476.2021.1885972

Yan, Z., and Brown, G. T. L. (2021). Assessment for Learning in the Hong Kong Assessment Reform: A Case of Policy Borrowing. Stud. Educ. Eval. 68, 100985. doi:10.1016/j.stueduc.2021.100985

Yan, Z., and Cheng, E. C. K. (2015). Primary Teachers' Attitudes, Intentions and Practices Regarding Formative Assessment. Teach. Teach. Educ. 45, 128-136. doi:10.1016/j.tate.2014.10.002

Yan, Z. (2018). How Teachers' Beliefs and Demographic Variables Impact on SelfRegulated Learning Instruction. Educ. Stud. 44, 564-577. doi:10.1080/ 03055698.2017.1382331

Yan, Z., Li, Z., Panadero, E., Yang, M., Yang, L., and Lao, H. (2021). A Systematic Review on Factors Influencing Teachers' Intentions and Implementations Regarding Formative Assessment. Assess. Educ. Principles, Pol. Pract. [Epub ahead of print]. doi:10.1080/0969594X.2021.1884042

Yan, Z. (2014). Predicting Teachers' Intentions to Implement School-Based Assessment Using the Theory of Planned Behaviour. Educ. Res. Eval. 20 (2), 83-97. doi:10.1080/13803611.2013.877394

Yan, Z., and Sin, K.-f. (2014). Inclusive Education: Teachers' Intentions and Behaviour Analysed from the Viewpoint of the Theory of Planned Behaviour. Int. J. Inclusive Educ. 18, 72-85. doi:10.1080/13603116.2012.757811

Yin, R. K. (1994). Case Study Research: Design and Methods. 2nd Edn. Thousand Oaks, CA: Sage Publications.

Conflict of Interest: The authors declare that the research was conducted in the absence of any commercial or financial relationships that could be construed as a potential conflict of interest.

Publisher's Note: All claims expressed in this article are solely those of the authors and do not necessarily represent those of their affiliated organizations, or those of the publisher, the editors and the reviewers. Any product that may be evaluated in this article, or claim that may be made by its manufacturer, is not guaranteed or endorsed by the publisher.

Copyright (๑) 2021 Yan, Xiao, Sin, Yang and Guo. This is an open-access article distributed under the terms of the Creative Commons Attribution License (CC BY). The use, distribution or reproduction in other forums is permitted, provided the original author(s) and the copyright owner(s) are credited and that the original publication in this journal is cited, in accordance with accepted academic practice. No use, distribution or reproduction is permitted which does not comply with these terms. 


\section{APPENDIX A. EXAMPLES OF CLASSIFIERS}

IN CHINESE

TABLE A1 | The classifiers discussed in Teresa's lesson are summarised below for readers to better understand the classroom episodes.

\begin{tabular}{|c|c|c|c|}
\hline Character & Pinyin & Yale & Meaning and principle use \\
\hline 位 & Wèi & wai2 & Polite classifier for people (attached to positions, not names), such as workers, director \\
\hline 輛 & Liàng & leung2 & Wheeled vehicles: Automobiles, buses, bicycles, etc. \\
\hline 個 & (Gè) & go3 & $\begin{array}{l}\text { Individual things, people - general, catch-all measure word (usage of this classifier in conjunction with any noun is generally } \\
\text { accepted if the person does not know the proper classifier) }\end{array}$ \\
\hline 隻 & Zhī & jek3 & Used before animals, such as birds, and cats, etc. \\
\hline
\end{tabular}

